\title{
High-Temperature Interaction of Molten Gray Cast Iron with $\mathrm{Al}_{2} \mathrm{O}_{3}-\mathrm{ZrO}_{2}-\mathrm{SiO}_{2}$ Ceramic
}

\author{
N. Sobczak, J.J. Sobczak, M. Kolev, L. Drenchev, P. Turalska, M. Homa, A. Kudyba, and G. Bruzda
}

(Submitted February 16, 2020; Accepted: 18 February 2020; published online March 16, 2020)

\begin{abstract}
High-temperature interaction between molten conventional gray cast iron (wt.\%: 4.1 C; $1 \mathrm{Si} ; 0.20 \mathrm{Mn} ; 0.03$ $\mathrm{S}$; $0.04 \mathrm{P}$, the rest $-\mathrm{Fe}$ ) and multiphase $\mathrm{Al}_{2} \mathrm{O}_{3}-\mathrm{ZrO}_{2}-\mathrm{SiO}_{2}$ ceramic substrate (wt.\%: $51.5 \mathrm{Al}_{2} \mathrm{O}_{3}, 33.8 \mathrm{ZrO}_{2}$, 13.3 $\mathrm{SiO}_{2}, \sim 1 \mathrm{NaO}_{2}, 0.15 \mathrm{Fe}_{2} \mathrm{O}_{3}+\mathrm{TiO}_{2}+\mathrm{CaO}$ ) was examined at a temperature of $1450{ }^{\circ} \mathrm{C}$ for $15 \mathrm{~min}$ under inert flowing gas atmosphere $(\mathrm{Ar}, 850-900 \mathrm{hPa})$ using a sessile drop method coupled with contact heating procedure. Melting, wetting behavior and solidification of gray cast iron sample were continuously recorded with a high-speed high-resolution CCD camera. Under conditions of this study, selected gray cast iron alloy does not wet the $\mathrm{Al}_{2} \mathrm{O}_{3}-\mathrm{ZrO}_{2}-\mathrm{SiO}_{2}$ ceramic forming the final contact angle with average value of $\theta_{\mathrm{f}} \sim 135^{\circ}$. The wetting kinetic curve was not smooth and its shape suggests the effect of substrate chemical heterogeneity due to multiphase composition of the substrate material. After the sessile drop test, the solidified drop was easily detached from the ceramic substrate along the drop-side interface showing a lack of bonding between the drop and the substrate. Structural characterization of the drop/substrate couple evidenced the nucleation and growth of graphite at the drop surface and at the drop/substrate interface taken place during solidification and resulting into the formation of discontinuous interfacial graphite layer.
\end{abstract}

Keywords gray cast iron, $\mathrm{Al}_{2} \mathrm{O}_{3}-\mathrm{ZrO}_{2}-\mathrm{SiO}_{2}$ ceramic, sessile drop method, wetting kinetics, interface, MMC

\section{Introduction}

High-temperature interaction between metal oxides and molten alloys takes place in several metallurgical processes such as metal casting (melt/crucible, melt/mold and melt/filter interactions) (Ref 1, 2), production of cast metal matrix composites (MMCs) containing oxide reinforcements (Ref 3, 4), reinforcing castings with ceramic inserts (Ref 5) and joining oxide-based ceramics (Ref 6). In these liquid-assisted processes, wettability plays a key role in the manufacture of highquality and defect-free products. Wetting phenomenon occurs when two media (liquid and solid) are brought together and it symbolizes the ability of a liquid to maintain contact with a solid surface.

Usually, wetting properties of materials are characterized by the value of contact angle $(\theta)$ established at the triple point,

Electronic supplementary material The online version of this article (https://doi.org/10.1007/s11665-020-04695-z) contains supplementary material, which is available to authorized users.

N. Sobczak, P. Turalska, M. Homa, A. Kudyba, and G. Bruzda, Lukasiewicz Foundry Research Institute, 73 Zakopianska Str, 30-418 Krakow, Poland; J.J. Sobczak, Faculty of Foundry Engineering, AGH University of Science and Technology, Reymonta 23, 30-059 Krakow, Poland; and Institute of Metal Science, Equipment and Technologies with Hydroaerodynamics Centre, Bulgarian Academy of Sciences, 67 Shipchenski Prohod Str, 1574 Sofia, Bulgaria; and M. Kolev and L. Drenchev, Institute of Metal Science, Equipment and Technologies with Hydroaerodynamics Centre, Bulgarian Academy of Sciences, 67 Shipchenski Prohod Str, 1574 Sofia, Bulgaria. Contact e-mail: natalia.sobczak@iod.krakow.pl. where three phases meet together, i.e., a liquid (L), a solid (S) and a gas (G) (Ref 7). The contact angle, as a quantitative measure of the wetting in a S/L system, can be expressed by the Young's equation, which describes the balance between interfacial tensions $\sigma_{S G}, \sigma_{S L}$ and $\sigma_{L G}$ at the tree-phase $\mathrm{S} / \mathrm{L} / \mathrm{G}$ contact:

$\sigma_{S G}=\sigma_{S L}+\sigma_{L G} \cos \theta$

Moreover, the contact angle characterizes also the S/L bonding (Ref 8) since it is related to the work of adhesion $\left(W_{a}\right)$ via the Young-Dupré equation:

$W_{a}=\sigma_{L G}(1+\cos \theta)$

In metal casting processes, non-wetting conditions $\left(\theta>90^{\circ}\right)$ resulting in week melt/crucible, melt $/$ mold and melt/filter interactions are required. On the contrary, in all liquid-assisted processes used for joining dissimilar materials (e.g., production of metal-ceramic composites by powder metallurgy, casting processes and additive manufacturing, joining ceramics, reinforcing of metal castings with ceramic inserts) good wetting $\left(\theta \ll 90^{\circ}\right)$ is a prerequisite property for ensuring desired metal-ceramic bonding and high-quality final products. Therefore, the investigation of the wetting phenomena at elevated temperatures constitutes one of the most important scientific aspects of high-temperature liquid-assisted materials processing stimulated by the demands of modern metallurgy and foundry industry (Ref 9-12).

In the last 50 years, extensive development has been done in the field of nonferrous MMCs, and nowadays, ferrous matrix composites have attracted many researchers due to technology developments, particularly those of iron foundry base (e.g., Ref $3-5)$. Recently, attention is given to reinforcing cast iron alloys using casting process through incorporation of ceramic particles (Ref 3,4$)$, porous preforms (Ref 3 ) or bulk inserts (Ref 5) into cast iron melt. Therefore, information on high-temperature interaction between molten cast iron alloys and different 
ceramics, as candidate materials for reinforcements, is of great practical importance. However, for oxides, there are only a few reports on wetting and interfacial phenomena with cast iron alloys (Ref 9-12). The aim of this study is to clarify the wetting behavior and reactivity of molten conventional gray cast iron in contact with $\mathrm{Al}_{2} \mathrm{O}_{3}-\mathrm{ZrO}_{2}-\mathrm{SiO}_{2}$ ceramic in terms of the successful manufacture of cast iron-based MMCs. Alumina-rich multiphase $\mathrm{Al}_{2} \mathrm{O}_{3}-\mathrm{ZrO}_{2}-\mathrm{SiO}_{2}$ refractory material has been selected as a potential ceramic reinforcement since it has beneficial combination of properties, i.e., improved strength, toughness, hardness and wear resistance over alumina alone combined with a lower cost than zirconia.

\section{Experimental}

A sessile drop method (Ref 7) was applied for real-time observation of melting, wetting behavior and solidification of conventional gray cast iron sample (in wt.\%: $4.1 \mathrm{C} ; 1 \mathrm{Si} ; 0.20$ $\mathrm{Mn} ; 0.03 \mathrm{~S}$; $0.04 \mathrm{P}$, the rest-Fe) placed on $\mathrm{Al}_{2} \mathrm{O}_{3}-\mathrm{ZrO}_{2}-\mathrm{SiO}_{2}$ (AZS) substrate. The wettability test was performed in an experimental complex for high-temperature studies of interaction between liquid metals and alloys and refractory materials at the Centre for High-Temperature Studies of the Foundry Research Institute (Poland) (Ref 13).

Directly before wettability test, the gray cast iron sample was cut from a bulk casting and cleaned mechanically and ultrasonically in isopropanol. The AZS substrate of $15 \times 15 \mathrm{~mm}$ size was cut from the AZS block (in wt.\%: 51.5 $\mathrm{Al}_{2} \mathrm{O}_{3}, 33.8 \mathrm{ZrO}_{2}, 13.3 \mathrm{SiO}_{2}, \sim 1 \mathrm{NaO}_{2}, 0.15 \mathrm{Fe}_{2} \mathrm{O}_{3}+$ $\left.\mathrm{TiO}_{2}+\mathrm{CaO}\right)$ produced by the Institute of Metal Science, Equipment and Technologies with Hydro-aerodynamics Centre (Bulgaria). The ceramic substrate was polished and also cleaned ultrasonically in isopropanol directly before testing.

The sessile drop test was performed in protective atmosphere (Ar, 99.999\%) using contact heating procedure, i.e., the cast iron sample was loaded into the vacuum chamber at room temperature by placing it on the ceramic substrate. After closing chamber and pumping up to a pressure of $p=2 \times 10^{-6} \mathrm{mbar}$, the metal/ceramic couple was contact heated with a rate of $15{ }^{\circ} \mathrm{C} / \mathrm{min}$ up to a temperature of $500{ }^{\circ} \mathrm{C}$, followed by introduction of flowing gas (Ar, 850-900 hPa). Next, the testing couple was heated with the same rate up to the experimental temperature of $1450{ }^{\circ} \mathrm{C}$, followed by isothermal heating at that temperature for $15 \mathrm{~min}$ before start of cooling process with a rate of $20{ }^{\circ} \mathrm{C} / \mathrm{min}$.

Throughout the entire test cycle, the images of the metal/substrate couple were recorded by a high-speed highresolution CCD camera MC1310 with a rate of $10 \mathrm{fps}$ (frame per second) and while cooling, the recording rate was $1 \mathrm{fps}$. The collected images were processed by ASTRA2 software developed by CNR-IENI, Italy (Ref 14, 15) for the determination of contact angles by an automatic image analysis. The contact angle values of the left $\left(\theta_{1}\right)$ and the right $\left(\theta_{\mathrm{r}}\right)$ sides of the drop were determined from the collected high-resolution images of the sessile drop test with systematic uncertainty of than $\pm 2^{\circ}$. The same images were also used for generating a real-time movie of the high-temperature test (see Supplementary material).

After wettability test, the solidified sessile drop couple was investigated by scanning electron microscopy (SEM) using TM3000 HITACHI device equipped with energy-dispersive Xray spectroscopy (EDS) analyzer Quantax 70. Structural observations were performed both on the drop and the substrate surfaces as well as on the cross-sectioned drop/substrate couple.

\section{Results}

Figure 1 shows the images of the metal/substrate couple during different stages of the sessile drop test, including that at room temperature (Fig. 1a), during melting gray cast iron sample (Fig. 1b), wetting behavior during drop formation (Fig. 1c) and wettability test (Fig. 1d,e) as well as upon drop solidification (Fig. 1f).

The results of wettability test are presented in Fig. 2 showing the change of the left and the right contact angle values with time. Immediately after melting gray cast iron (a)

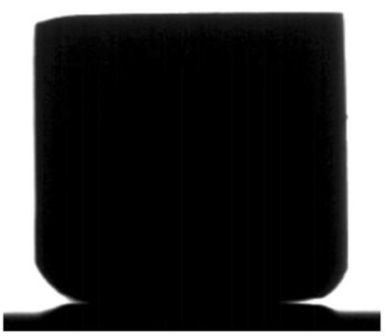

(d)

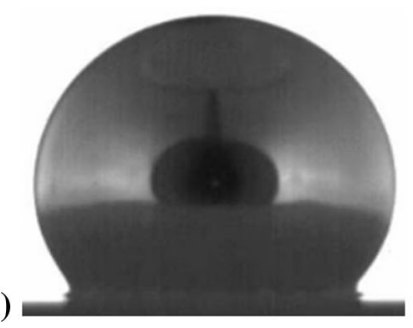

(b)

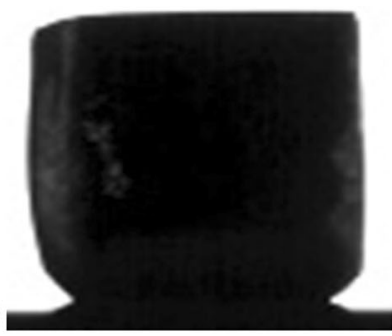

(e)

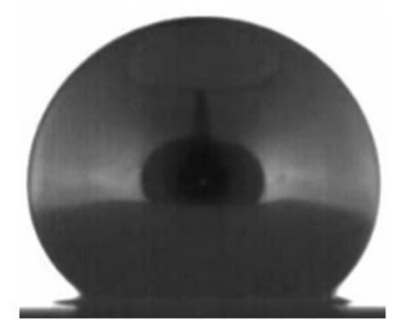

(c)

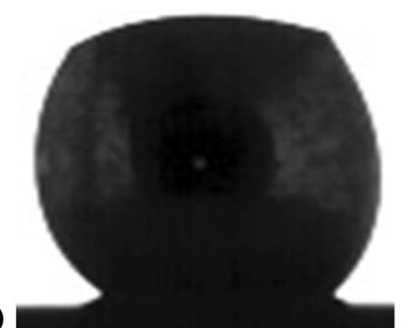

(f)

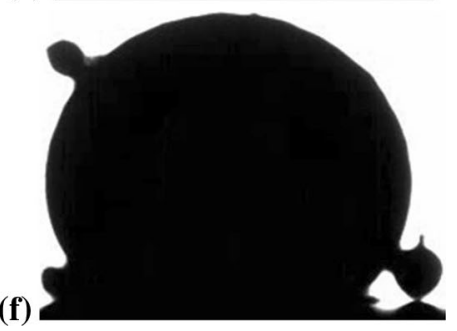

Fig. 1 Images of conventional gray cast iron on the AZS substrate recorded during the sessile drop test: (a) beginning of heating, $21{ }^{\circ} \mathrm{C}$; (b) beginning of melting of cast iron sample, $1130{ }^{\circ} \mathrm{C}$; (c) formation of the drop, $1145{ }^{\circ} \mathrm{C}$; (d) start of isothermal heating at $1450{ }^{\circ} \mathrm{C}(t=0 \mathrm{~s})$; (e) end of isothermal heating at $1450{ }^{\circ} \mathrm{C}(t=15 \mathrm{~min})$; (f) end of the test, $400{ }^{\circ} \mathrm{C}$ 


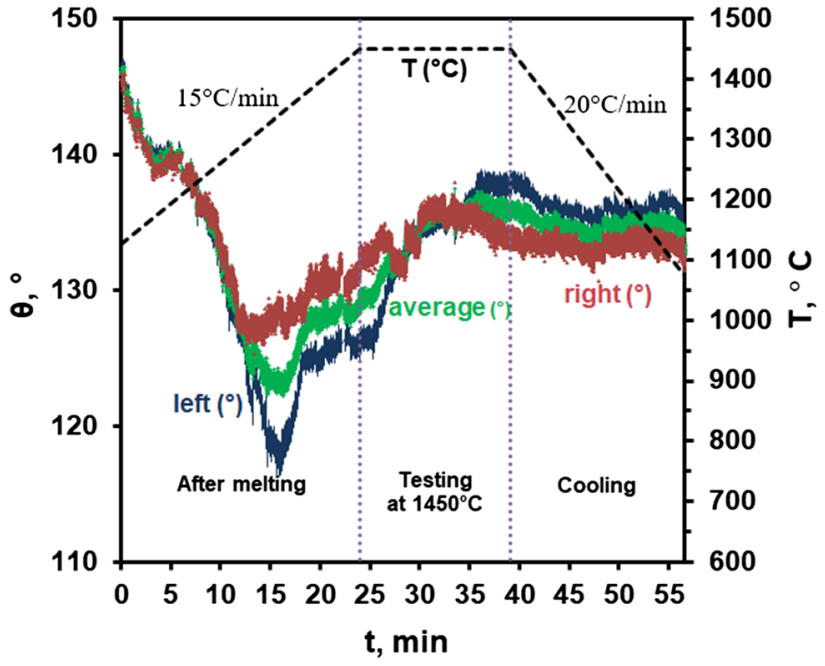

Fig. 2 Wettability kinetics of molten conventional gray cast iron on AZS substrate during heating to and at $1450{ }^{\circ} \mathrm{C}$

sample, it forms a high contact angles $\theta_{1}=\theta_{\mathrm{r}} \sim 145^{\circ}$, which both decrease with time during further heating. Moreover, during this stage, left and right contact angles become dissimilar and their difference $\left(\Delta \theta=\theta_{1}-\theta_{\mathrm{r}}\right)$ increases with time until complete melting of the sample. Based on the real-time observation of the sessile drop couple, we may conclude that there are three possible factors acting together and resulting in such behavior, i.e., 1) non-uniform melting of the gray cast iron sample, 2) physical (roughness) and 3) chemical heterogeneity of the substrate surface due to the presence of tree phases of dissimilar physical properties, i.e., $\mathrm{Al}_{2} \mathrm{O}_{3}, \mathrm{~m}-\mathrm{ZrO}_{2}$ and $\mathrm{t}-\mathrm{ZrO}_{2}$.

The next stage was accompanied with decrease in $\Delta \theta$ value and the formation of perfectly symmetrical drop with corresponding $\Delta \theta=0^{\circ}$ in about 5 th minute at $1450{ }^{\circ} \mathrm{C}$. The first average contact angle $\theta=\left(\theta_{1}+\theta_{\mathrm{r}}\right) / 2$ formed at the test temperature $\left(1450{ }^{\circ} \mathrm{C}, t=0 \mathrm{~s}\right)$ was $\theta_{0} \sim 130^{\circ}$. During isothermal heating at that temperature for $15 \mathrm{~min}$, both $\Delta \theta$ value and the average contact angle value were slightly increased to the final value of $\theta_{\mathrm{f}} \sim 135^{\circ}$. Thus, one may conclude that under testing conditions of this study, the selected gray cast iron alloy does not wet the AZS substrate showing the contact angle $\theta \gg 90^{\circ}$.

Another very important fact was noted after cooling the couple to room temperature, i.e., the solidified drop was found separated from the substrate. This observation represents experimental evidence of weak bonding established during high-temperature test between the cast iron drop and the AZS substrate. Thus, one may conclude that weak bonding is in a good agreement with experimental results of non-wetting behavior of examined system. However, the detailed analysis of the real-time behavior of the couple during high-temperature test (see a movie in Supplementary material and extracted images in Fig. 3) supported our predictions that for examined couple, the most critical moment for establishing bonding between the drop and the substrate was the solidification of gray cast iron drop accompanied with increase of its volume. This positive shrinkage effect is demonstrated by the phenomenon of squeezing smaller "daughter" droplets from the "mother" drop in the final stage of its solidification well distinguished in Fig. If and Fig. 3a and b. Therefore, significant CTE (coefficients of thermal expansion) mismatch of the
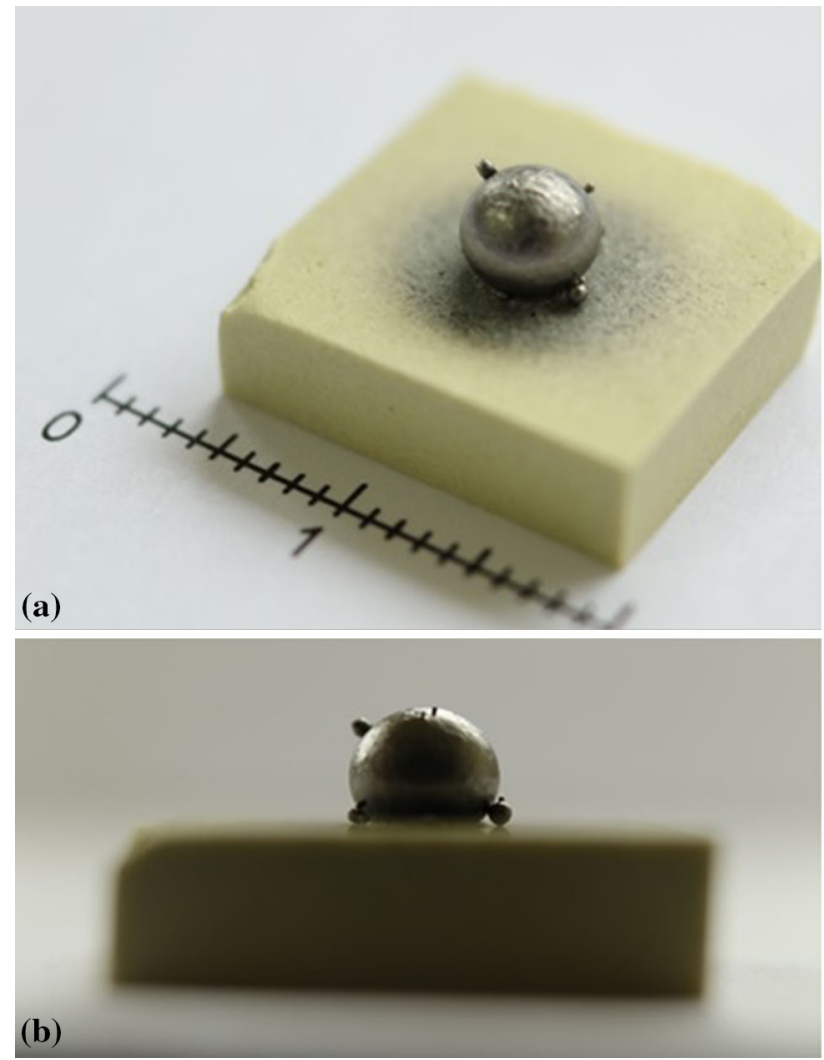

Fig. 3 Photograph of solidified drop after high-temperature wetting test at $T=1450{ }^{\circ} \mathrm{C}$ : (a) top view; (b) side view of small droplets on the surface of main drop

alloy (volume expansion) and the ceramic substrate (volume shrinkage) at the moment of the drop solidification and also during subsequent cooling of the solidified drop/substrate couple (dissimilar CTE values for the ceramic and the alloy) contributes to the debonding of two materials.

SEM observations of the couple from the top view (Fig. 4ad) show that the surface of the drop is covered with large black graphite blots while occasionally between them there are small daughter droplets of white color growing from white region of the mother drop. This white region as well as small daughter droplets correspond to lower melting temperature part of the drop as they were squeezed from solidifying drop at the last moment of solidification due to expansion of solidifying gray cast iron. The substrate surface around the drop does not indicate any important structural changes (Fig. 4a) thus suggesting that the dark ring in the vicinity of the drop, well distinguished in Fig. 3a, is related with evaporation and deposition from the drop.

SEM/EDS analysis of cross-sectioned couple revealed no changes in the substrate structure after high-temperature test since the phase composition remains the same, composed of three binary oxides, e.g., $\mathrm{Al}_{2} \mathrm{O}_{3}, \mathrm{~m}-\mathrm{ZrO}_{2}$ and $\mathrm{t}-\mathrm{ZrO}_{2}$ phases (Fig. 5a, b). Under law magnification (Fig. 5a), the microstructure of the drop looks homogeneous while under higher magnifications (Fig. 5b-d), less graphite precipitates are in the drop in the vicinity of its surface (Fig. 5c) and near the drop/substrate interface (Fig. 5d). This effect might be related with experimentally evidenced nucleation and growth of graphite at the drop surface (already mentioned above) and at the drop/substrate interface (see explanation below), both 


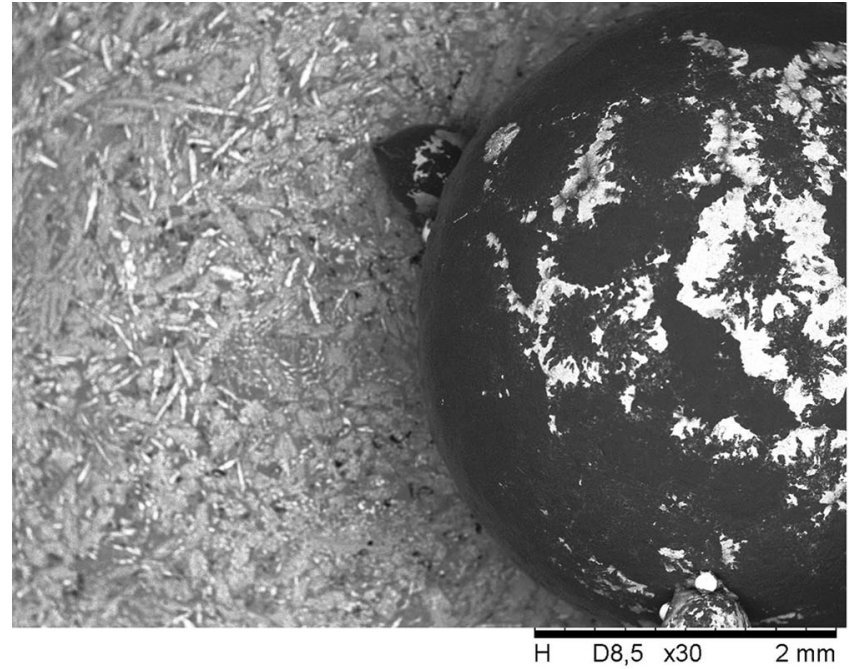

2866

(a)

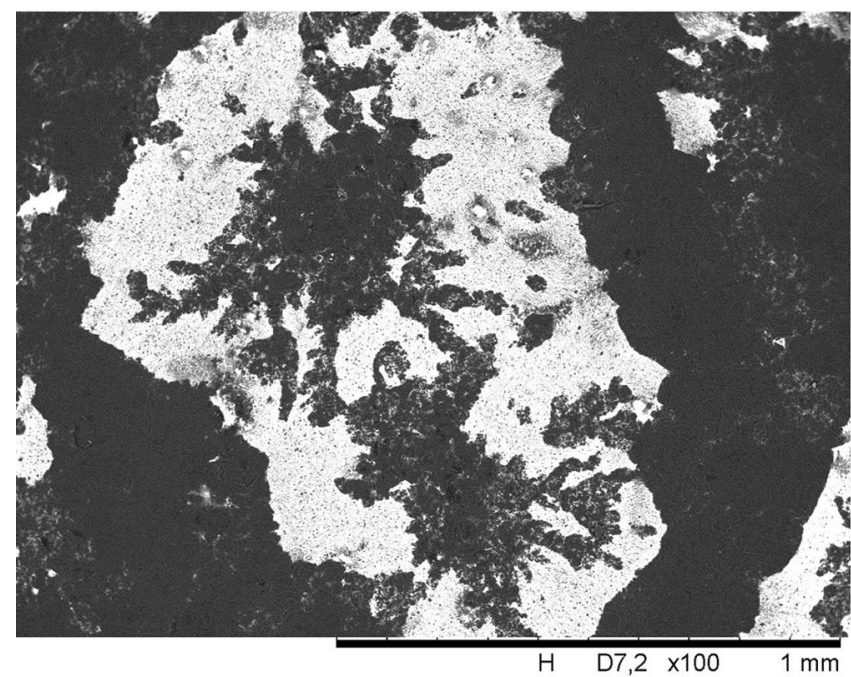

2866

(c)

Fig. 4 SEM views of drop surface under different magnifications

resulting in the carbon depletion of the drop regions surrounding graphite precipitates.

The detailed analysis of interfacial and near-interfacial regions (Fig. 6) exposed the presence of dark discontinuous layer up to about $35 \mu \mathrm{m}$ thickness of which EDS analysis showed the appearance of carbon only. It is believed that this layer was formed during cooling through nucleation and growth of graphite phase at the interface, i.e., similar to that at the open surface of the drop. SEM observations showed that the debonding of the drop/substrate couple during cooling took place along the drop-side interface while a good bonding was established between the substrate and the graphite layer at the substrate-side interface. Nevertheless, based on the current observations, it is difficult to identify which phase of the substrate plays a role of a nucleation site for graphite because of discontinuous character of the graphite layer with its fragments locally detached from the substrate, most probably, during sample preparation for structural characterization (cutting and polishing). It should be highlighted that under magnifications

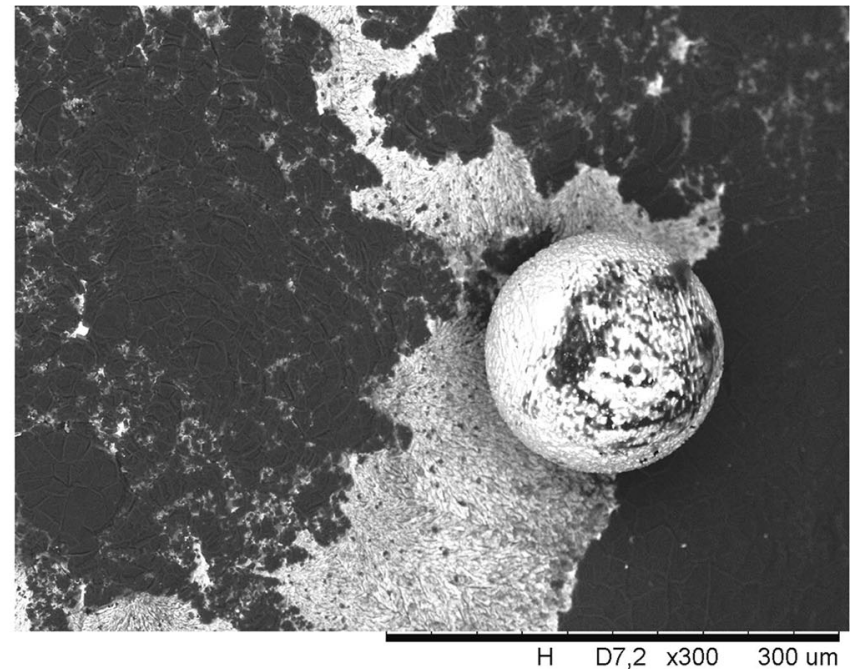

2866

(b)

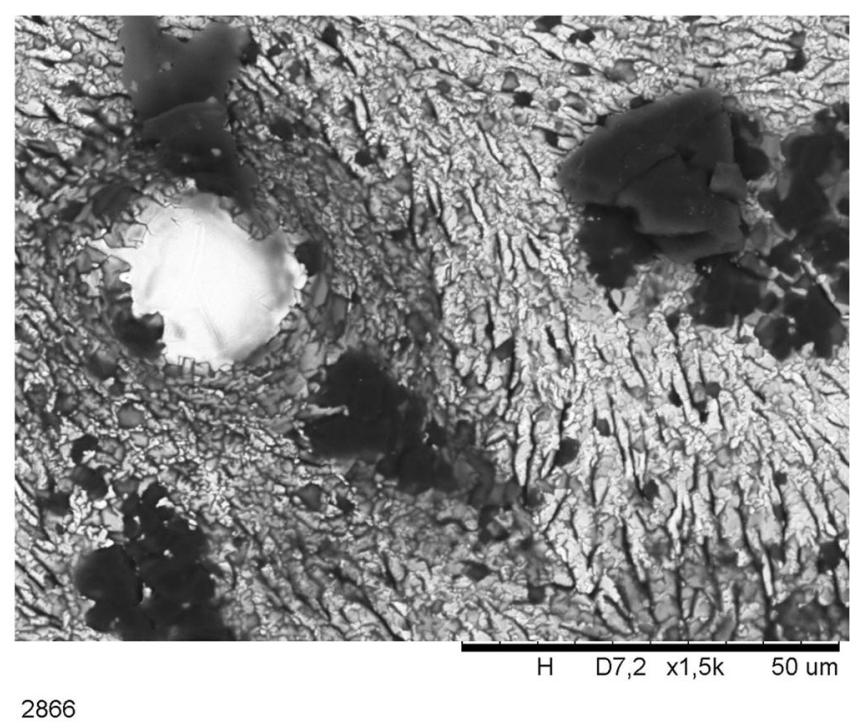

(d)

used in this study for SEM observations (up to $5000 \times$ ), we did not distinguish any interfacial reaction products.

Local chemical analysis in different regions of the drop proved that the alloy matrix, particularly near the interface, contains about 3.3-3.9 Al, 0.3-0.6 Zr and 0.3-0.6 Na (at.\%). No separate particles of new phases were identified in the solidified drop. These observations put forward a slight selective dissolution of the substrate constituents (mainly $\mathrm{Al}_{2} \mathrm{O}_{3}$ and $\mathrm{ZrO}_{2}$ ) in molten drop and suggest that no chemical reactions take place between selected gray cast iron alloy and AZS ceramic.

\section{Discussion}

Contrary to pure iron, only a few publications are available in the literature for information on contact angles and interface structures formed between molten cast iron alloys on oxidebased refractories. For $\mathrm{Al}_{2} \mathrm{O}_{3}, \mathrm{SiO}_{2}$ and $\mathrm{Al}_{2} \mathrm{O}_{3}-\mathrm{SiO}_{2}$ substrates 


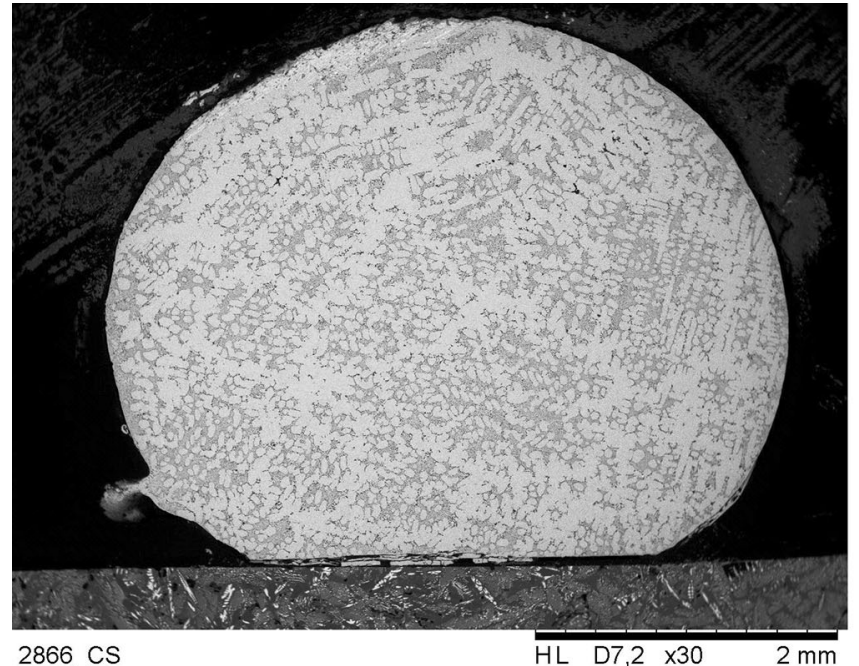

(a)

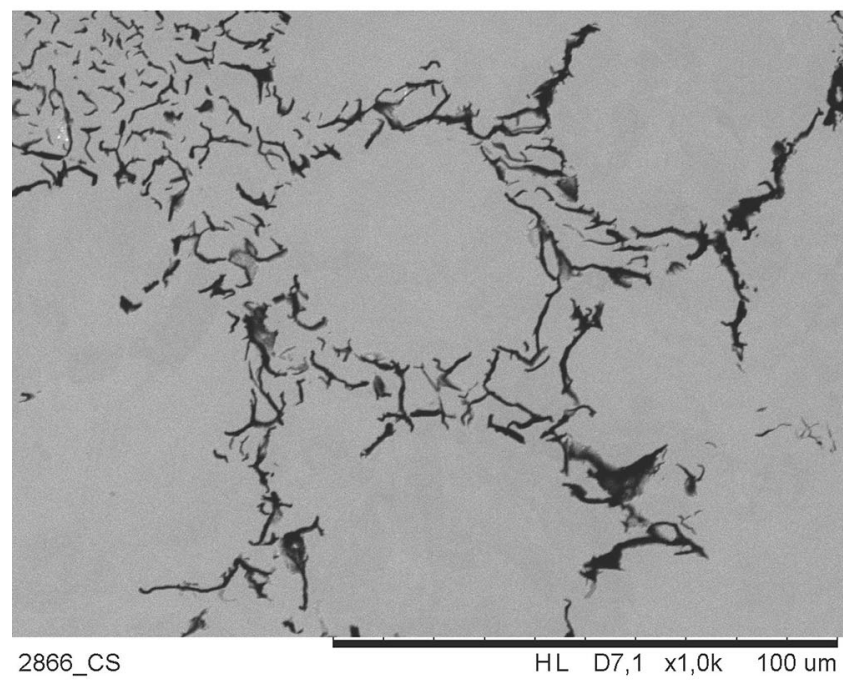

(c)

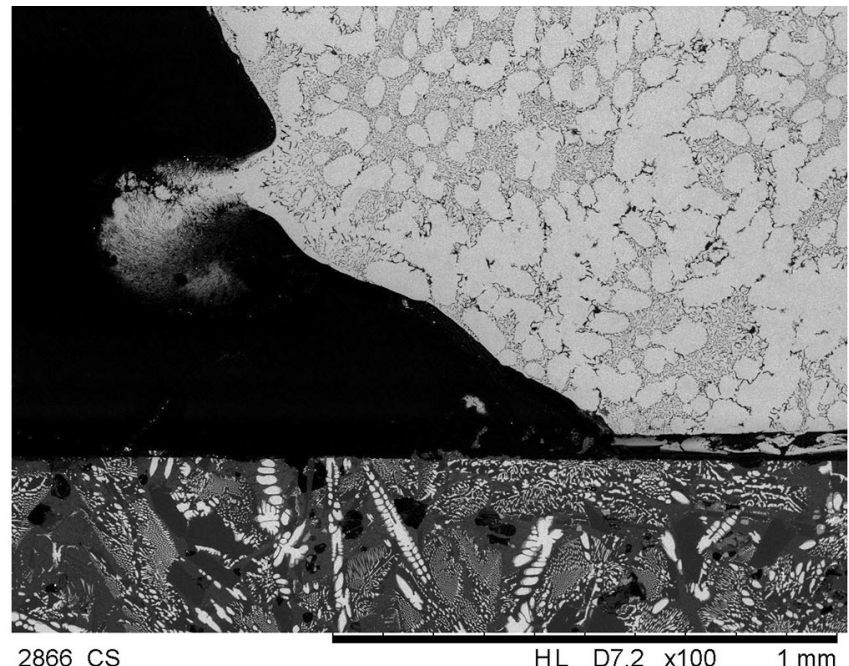

(b)

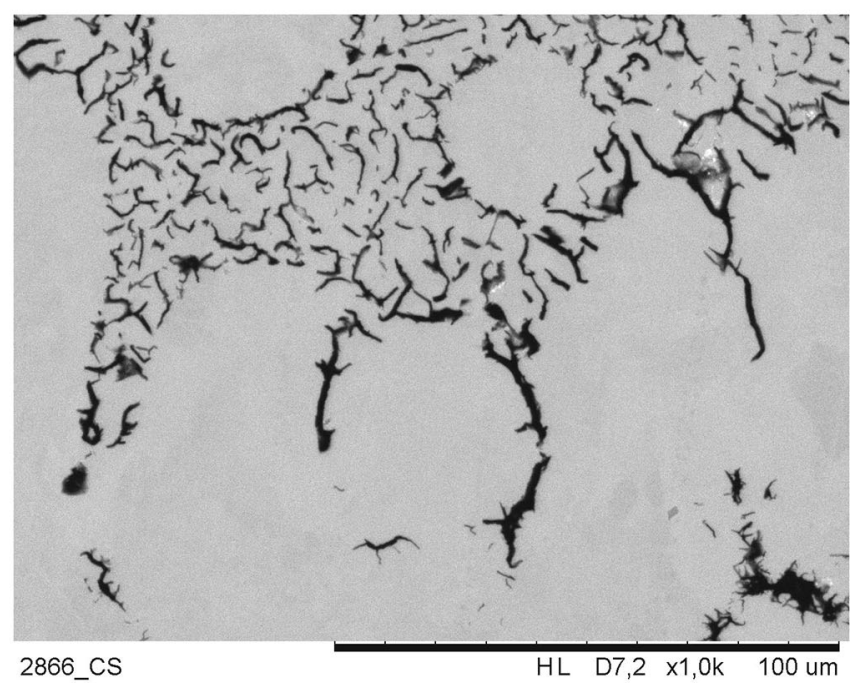

(d)

Fig. 5 SEM views of cross-sectioned couple: (a) general view; (b) near triple line; (c) in the center of the drop; (d) in the bottom of the drop near the drop/substrate interface

(Ref 9-11), non-wetting behavior have been reported with the contact angle values from $105^{\circ}$ to $140^{\circ}$, depending on temperature, atmosphere and porosity of the substrate. From this point of view, the results of our study are compatible to literature data.

First available reports on the interaction of cast iron melts with $\mathrm{Al}_{2} \mathrm{O}_{3}$ and $\mathrm{SiO}_{2}$ (Ref 9, 10) showed the presence of a new unidentified phase at the solidified drop/substrate interfaces. In case of $\mathrm{Al}_{2} \mathrm{O}_{3}$ substrate, this phase was easily separated from the substrate and only with difficulty from the metal. On the contrary, a new phase was well bonded to the $\mathrm{SiO}_{2}$ and easily detached from the metal drop. Klyachko et al. (Ref 9) found these observations as experimental evidence of more rapid wetting of the molten cast iron on $\mathrm{Al}_{2} \mathrm{O}_{3}$ substrate than on $\mathrm{SiO}_{2}$ one.

Pitak et al. (Ref 11) examined wetting properties of aluminosilicate (mullite, kaolin) refractories of varied porosity by molten cast iron $(3.7 \% \mathrm{Fe}, 4.8 \% \mathrm{C}, 0.5 \% \mathrm{P}, 0.85 \% \mathrm{Si}$, $0.05 \% \mathrm{~S}, 0.1 \%$ - other elements) over the temperature range of
$1140-1500{ }^{\circ} \mathrm{C}$ and different holding times. For the dense substrate of only $0.1 \%$ porosity, the contact angle decreased from $137^{\circ}$ to $122^{\circ}$ in $45 \mathrm{~min}$ at $1140{ }^{\circ} \mathrm{C}$ while at 1350 and $1500{ }^{\circ} \mathrm{C}$, it decreased during the first $5-15 \mathrm{~min}$ and then remained unchanged for the total holding time of $45 \mathrm{~min}$. At all temperatures, non-wetting behavior was recorded with the final contact angles in the range of $119-122^{\circ}$. Pitak et al. (Ref 11) used this fact for the proof of identity of the interaction between molten cast iron and dense mullite substrate as the weak one. Comparative studies under the same testing conditions on fused kaolin substrates of $3 \%$ of open porosity evidenced smaller contact angles, especially at 1350 and $1500{ }^{\circ} \mathrm{C}\left(115^{\circ}\right.$ and $105^{\circ}$, respectively), as evidence of a certain extent interaction of the melt with fused kaolin. Moreover at $1500{ }^{\circ} \mathrm{C}$, the surface of the kaolin substrate was covered with a thin glass layer while the drop showed boiling behavior accompanied with strong spattering as a result of strong interaction in the system.

Sessile drop tests performed by Bacior et al. (Ref 12) with molten cast iron (originally vermicular graphite cast iron, 


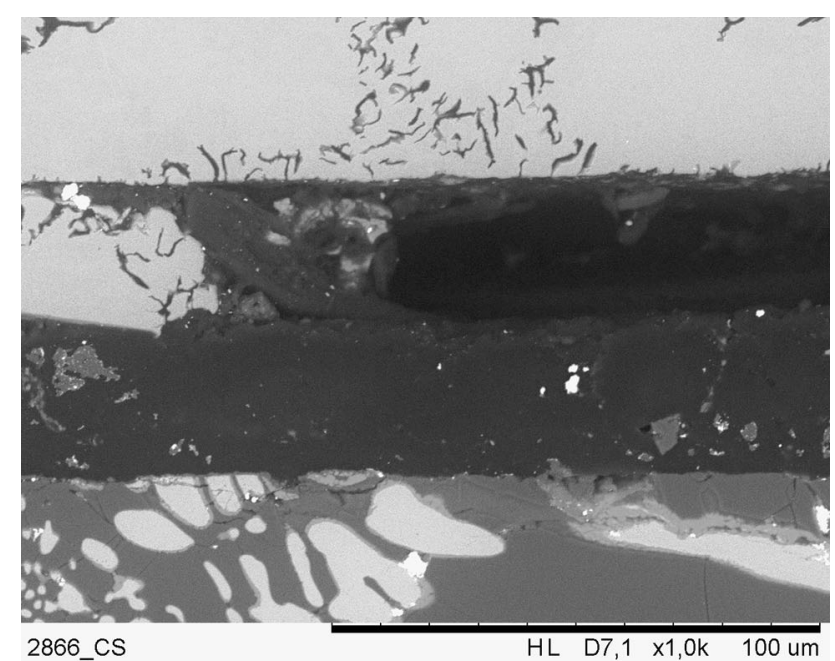

(a)

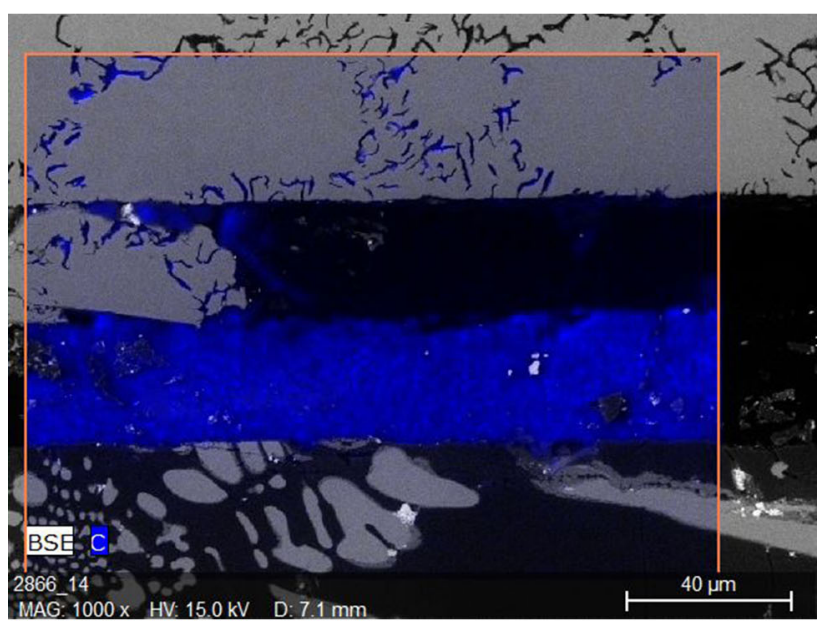

(b)

Fig. 6 SEM view of cross-sectioned couple in the interfacial region (b) and corresponding mapping of distribution of carbon across the section (b)

containing in wt.\%: $3.70 \mathrm{C}, 2.30 \mathrm{Si}, 0.44 \mathrm{Mn}, 0.054 \mathrm{P}$, $0.017 \mathrm{Mg}, 0.015 \mathrm{~S}$ ) and commercial polycrystalline alumina $\mathrm{Al}_{2} \mathrm{O}_{3}$ substrate $(99.70 \%$ purity and less than 3 vol.\% porosity) in an inert flowing gas atmosphere ( $\mathrm{Ar}, 850-900 \mathrm{hPa}$ ) showed that after holding time of $15 \mathrm{~min}$ at a temperature of $1450{ }^{\circ} \mathrm{C}$, the system is non-wetting with corresponding high contact angle of $131^{\circ}$. Structural characterization of the drop/substrate interface revealed the reaction zone $(\sim 70 \mu \mathrm{m})$ formed at the substrate-side interface due to interaction between $\mathrm{Al}_{2} \mathrm{O}_{3}$ and molten cast iron. Moreover, the discontinuous layer of about $26 \mu \mathrm{m}$ thick composed mainly of carbon and located at the drop-side interface, was well distinguished. The formation of interfacial graphite layer reported by Bacior et al. (Ref 12) is consistent with the results of this study, especially taking into account the same testing procedure and the same testing conditions used in both studies. The different location of wellbonded interface in this study vs the previous work (Ref 12) is related with dissimilar substrate materials used. In this study, the graphite layer is well bonded to the $\mathrm{Al}_{2} \mathrm{O}_{3}-\mathrm{ZrO}_{2}-\mathrm{SiO}_{2}$ substrate while debonding took place along the drop-side interface. On the contrary, the previous work (Ref 12) evidenced a good bonding at the drop-side interface with corresponding debonding along the substrate-side interface.

Based on the results of this study, we may conclude that under applied testing conditions, weak interaction takes place between selected cast iron alloy and $\mathrm{Al}_{2} \mathrm{O}_{3}-\mathrm{ZrO}_{2}-\mathrm{SiO}_{2}$ ceramic accompanying with slight dissolution of the substrate in molted drop. The formation of discontinuous graphite layer during solidification of molten drop contributes to a weak bonding between the drop and the substrate.

The above observations suggest that for the selected couple of materials, the improvement of their physico-chemical and thermomechanical compatibilities are needed in order to produce high-performance metal matrix composites by liquidassisted processes using gray cast iron (as a matrix) and $\mathrm{Al}_{2} \mathrm{O}_{3}$ $\mathrm{ZrO}_{2}-\mathrm{SiO}_{2}$ ceramic (as a reinforcing phase or insert in the casting components). On the other hand, both non-wetting and non-reactive character of examined couple advises the applicability of $\mathrm{Al}_{2} \mathrm{O}_{3}-\mathrm{ZrO}_{2}-\mathrm{SiO}_{2}$ refractory in foundry practice of the selected molten cast iron, e.g., as a material for porous ceramic filters used to remove non-metallic inclusions from molten metal and to improve the quality of final castings.

\section{Summary}

Under testing conditions in the sessile drop test of this study, the selected conventional gray cast iron alloy does not wet alumina-based $\mathrm{Al}_{2} \mathrm{O}_{3}-\mathrm{ZrO}_{2}-\mathrm{SiO}_{2}$ ceramic and after melting and holding at $T=1450{ }^{\circ} \mathrm{C}$ for $15 \mathrm{~min}$, it forms a high contact angle of $\sim 135^{\circ}$. After the sessile drop test, the solidified drop was easily detached from the ceramic substrate showing a lack of bonding between them.

Structural characterization of the drop/substrate couple by SEM + EDS analysis evidenced the nucleation and growth of graphite at the drop surface and at the drop/substrate interface resulting in the formation of discontinuous interfacial graphite layer well bonded with the substrate. Non-wetting behavior accompanied with a lack of any interfacial reaction products and slight selective dissolution of the substrate constituents in molten drop suggests a weak interaction between the selected alloy and $\mathrm{Al}_{2} \mathrm{O}_{3}-\mathrm{ZrO}_{2}-\mathrm{SiO}_{2}$ ceramic. Moreover, significant CTE mismatch between the alloy and the ceramic, particularly during alloy solidification, contributes to debonding of the drop/substrate couple that takes place along the drop-side interface.

These findings suggest that for liquid-assisted processes of metal matrix composites using gray cast iron (as a matrix) and $\mathrm{Al}_{2} \mathrm{O}_{3}-\mathrm{ZrO}_{2}-\mathrm{SiO}_{2}$ ceramic (as a reinforcing phase or insert in the casting components), the improvement of physico-chemical and thermomechanical compatibilities between the selected couple of materials are needed through improvement of wetting properties and optimal design of structure and chemistry of interfaces.

\section{Acknowledgments}

The authors are grateful for financial support of National Science Centre of Poland within OPUS program (UMO-2015/17/ B/ST8/03391). This work was partially supported by the European Regional Development Fund within the OP "Science and Educa- 
tion for Smart Growth 2014-2020", Project CoE "National center for/of mechatronics and clean technologies" (No BG05M2OP0011.001-0008-C01). M. Kolev wishes to thank for research fellowship from the European Virtual Institute on Knowledge-based Multifunctional Materials AISBL (KMM-VIN).

\section{Open Access}

This article is licensed under a Creative Commons Attribution 4.0 International License, which permits use, sharing, adaptation, distribution and reproduction in any medium or format, as long as you give appropriate credit to the original author(s) and the source, provide a link to the Creative Commons licence, and indicate if changes were made. The images or other third party material in this article are included in the article's Creative Commons licence, unless indicated otherwise in a credit line to the material. If material is not included in the article's Creative Commons licence and your intended use is not permitted by statutory regulation or exceeds the permitted use, you will need to obtain permission directly from the copyright holder. To view a copy of this licence, visit http://creativecommons.org/licenses/by/4.0/.

\section{References}

1. N. Sobczak, J. Sobczak, R. Asthana, and R. Purgert, The Mystery of Molten Metal, China Foundry, 2010, 7(4), p 425-437

2. J.L. Lewandowski and M. Holtzer, An Investigation of Wettability and Work of Adhesion in Ferrous Alloy/Moulding Sand Systems, Cast Met., 1995, 8(3), p 159-165

3. R.M. Hathaway, P. Rohatgi, N. Sobczak, J. Sobczak, Ferrous composites: a review. in Proceedings of 2nd International Conf. High Temperature Capillarity, ed. by N. Eustathopoulos, N. Sobczak, 29 June-2 July 1997, Cracow, Poland, Foundry Research Institute, 1998, p 267-276
4. M. Bay, Y. Su, S-W. Gong, Preparation and properties of high chromium cast iron matrix composites reinforced by zirconium corundum particles, in Proceedings of 2nd International Conference on Test, Measurement and Computational Method (TMCM-2017), (2017), p 365-369

5. N. Dulska, A. Studnicki, and J. Szajnar, Reinforcing Cast Iron with Composite Insert, Arch. Metall. Met., 2017, 62(1), p 355-357

6. J. Intrater, Review of Some Processes for Ceramic-to-Metal Joining, Mater. Manuf. Process., 1993, 8(3), p 353-373

7. N. Sobczak, M. Singh, and R. Asthana, High-Temperature Wettability Measurements in Metal/Ceramic Systems: Some Methodological Issues, Curr. Opin. Solid State Mater. Sci., 2005, 9(4-5), p 241-253

8. N. Sobczak, R. Asthana, The role of interfacial phenomena in wettingbonding relationship in $\mathrm{Al} /$ ceramic couples, Surface, Interfaces and the Science of Ceramic Joining, Ceramic Transactions, vol. 158, K. Scott Weil, I.E. Reimains, C.A. Lewinsohn, Ed., 2005, p 3-27

9. Y.A. KIyachko, L.L. Kunin, Zhurnal Prikladnoy Khimii, 1947, 22(7), p 707-715 (in Russian)

10. S.I. Popel, Foundry Theory and Practice Masbgiz, Sverdlovsk, 1959, p 162-187 (in Russian)

11. N.V. Pitak, R.M. Fedoruk, R.S. Shulyak, and T.P. Khmelenko, Wetting of Aluminosilicate Refractories with Cast Iron, Refractories, 1978, 19(5-6), p 301-304

12. M. Bacior, N. Sobczak, M. Homa, P. Turalska, A. Kudyba, G. Bruzda, R. Nowak, and A. Pytel, High-Temperature Interaction of Molten Vermicular Graphite Cast Iron with $\mathrm{Al}_{2} \mathrm{O}_{3}$ Substrate, Trans. Foundry Res. Inst., 2017, LVII(4), p 375-384

13. N. Sobczak, R. Nowak, W. Radziwill, J. Budzioch, and A. Glenz, Experimental Complex for Investigations of High Temperature Capillarity Phenomena, Mater. Sci. Eng. A, 2008, 495(1-2), p 43-49

14. ASTRA Reference Book, IENI, Report, 2007

15. L. Liggieri and A. Passerone, An Automatic Technique for Measuring the Surface Tension of Liquid Metals, High Temp. Technol., 1989, 7(2), p $82-86$

Publisher's Note Springer Nature remains neutral with regard to jurisdictional claims in published maps and institutional affiliations. 